Article

\title{
The Implementation of the REACH Authorisation Procedure on Chemical Substances of Concern: What Kind of Legitimacy?
}

\author{
Christoph Klika \\ Faculty of Arts and Social Sciences, Maastricht University, 6200MD Maastricht, The Netherlands; \\ E-Mail: c.klika@maastrichtuniversity.nl
}

Submitted: 2 June 2014 | In Revised Form: 20 September 2014 | Accepted: 19 November 2014 |

Published: 31 March 2015

\begin{abstract}
With the increasing "agencification" of policy making in the European Union (EU), normative questions regarding the legitimacy of EU agencies have become ever more important. This article analyses the role of expertise and legitimacy with regard to the European Chemicals Agency ECHA. Based on the REACH regulation, so-called Substances of Very High Concern (SVHCS) are subject to authorisation. The authorisation procedure aims to ensure the good functioning of the internal market, while assuring that risks of SVHCs are properly controlled. Since ECHA has become operational in 2008, recurring decisions on SVHCs have been made. The question posed in this article is: to what extent can decision making in the REACH authorisation procedure be assessed as legitimate? By drawing on the notion of throughput legitimacy, this article argues that decision making processes in the authorisation procedure are characterized by insufficient legitimacy.
\end{abstract}

\section{Keywords}

authorisation; ECHA; expertise; REACH; SVHCs; throughput legitimacy

\section{Issue}

This article is part of the special issue "The Role of Expert Knowledge in EU Executive Institutions", edited by Professor Åse Gornitzka (University of Oslo, Norway) and Dr. Cathrine Holst (University of Oslo, Norway).

(C) 2015 by the author; licensee Cogitatio (Lisbon, Portugal). This article is licensed under a Creative Commons Attribution 4.0 International License (CC BY).

\section{Introduction}

In the European Union (EU), regulatory tasks have been increasingly delegated to decentralized agencies since the 1990s (see e.g., Busuioc, Groenleer, \& Trondal, 2012). With the increasing "agencification" of policy making, normative questions regarding the legitimacy of EU agencies have become ever more important (see Rittberger \& Wonka, 2011). This is particularly the case with regulatory agencies which are de facto decision makers without having de jure decision making powers (Gehring \& Krapohl, 2007; Klika, Kim, \& Versluis, 2013; Krapohl, 2004). The European Medicines Agency EMA and the European Food Safety Authority EFSA are wellknown cases. While these normative questions somewhat reflect the debate about the alleged democratic deficit of the EU, the issue of EU agency legitimacy is a special case of this debate. In general, agencies are special because technical tasks are delegated to insulate decision making processes from electoral cycles and partisan politics. Such insulation limits the legitimacy of agencies because they are, in contrast to governments, not directly linked to democratic representation based on elections. In order to compensate for this limitation, agencies are expected to provide more effective problem solving (Majone, 1996). It is assumed that agencies are better able to process technical information, meaning that expertise, rather than democratic representation, is their main source of legitimacy (Sabatier, 1978; European Commission, 2008).

In this article, I analyse the role of expertise and legitimacy with regard to the European Chemicals Agency ECHA. The creation of the agency is based on the socalled REACH regulation on industrial chemicals, which can be understood as the flagship of EU chemicals policy (European Parliament, \& Council of the European 
Union, 2006). REACH was adopted in December 2006, after a lengthy and controversial legislative process (e.g., Pesendorfer, 2006; Selin, 2007). Due to the complexities of chemicals policy, REACH combines different regulatory instruments and ECHA has varying tasks related to these instruments. The analysis here is restricted to the authorisation procedure dealing with socalled Substances of Very High Concern (SVHCs). As a first step, I will analyse the role of ECHA in this procedure and then I proceed to answer two research questions: How can we assess the legitimacy of EU agency decision making and to what extent is decision making in the REACH authorisation procedure legitimate? After the conceptual discussion, I present empirical material supporting the argument that agencies have the potential of increasing the legitimacy of decision making based on set rules and procedures. However, decision making processes in the authorisation procedure are characterized by insufficient legitimacy because such rules and procedures have been altered during the implementation of the authorisation procedure. As a result, and regardless of concrete decision outcomes, vital aspects of legitimacy such as inclusiveness and transparency are negatively affected, which in turn reduces the acceptability of these outcomes for multiple stakeholders.

A vast literature, in the natural sciences, law as well as political science, deals with the highly controversial legislative process and the governance arrangements enshrined in REACH. Yet, in-depth analyses of how decision making unfolds in the implementation of REACH by and through ECHA is still relatively patchy, despite increasing scholarly attention (see e.g., Bergkamp, 2013; Lee, 2014a; Ossege, 2014; Scott, 2009; Stokes \& Vaughan, 2013). Hence, this article contributes to this literature by presenting empirical evidence of implementing the REACH authorisation procedure. The analysis draws on legislative texts, a wide range of policy documents, technical guidance and minutes of the respective ECHA decision making bodies. In order to increase the validity of the analysis, the documentary evidence is complemented by semi-structured interviews with policy makers, experts and stakeholders. In order to ensure reliability, the selection of interviewees was based on the set of actors which are formally entitled to make decisions in the authorisation procedure, i.e., the Member States (MS), the European Commission (COM) as well as ECHA. In addition, interviews were held with representatives of stakeholder organisations (STO), the European Parliament and experts on EU chemicals policy (EXP). The interviews are cited in-text with the acronyms given and numbered in case of multiple respondents. The empirical evidence and analysis cover a crucial period (as explained below) - from mid2008 to the end of 2012-regarding the implementation of REACH.

\section{The Case of ECHA and the Authorisation of Substances of Very High Concern}

At the core of EU chemicals policy is the classification of hazardous substances (see e.g., Heyvaert, 1999), i.e., substances that might be toxic, carcinogenic or persisting in the environment. In the regulatory regime prior to REACH (henceforth the old regime), thousands of hazardous substances have been classified at the EU level. Today, these substances are listed in the regulation on Classification, Labelling and Packaging (CLP), a complementary regulation to REACH (European Parliament, \& Council of the European Union, 2008). The list of classified substances is regularly updated through procedures laid down in the CLP regulation. In REACH terminology, hazardous substances are referred to as Substances of Very High Concern (SVHCs). Three types of SVHCs are distinguished (Art. 57 REACH): carcinogens, mutagens and substances toxic for reproduction (CMRs), substances persisting and accumulating in the environment (PBTs), as well as substances of equivalent concern (ECs). The authorisation procedure aims to ensure the good functioning of the internal market, while assuring that risks of SVHCs are properly controlled (Art. 55 REACH). This means that certain industrial uses of SVHCs might be banned due to their risks, yet without overly harming the chemicals industry that would have to substitute these substances for suitable alternatives.

In addition to classification, the old regime already entailed the possibility to limit the use of hazardous substances through legislative restrictions. To this end, Member States' regulatory authorities had the responsibility to conduct extensive risk assessment on prioritized substances, which then had to be endorsed by various expert committees. This cumbersome procedure put the burden of proof regarding substances' risk on Member States' regulatory authorities. Decision making not only suffered from such cumbersome procedures, but also from limited availability of information. Under the old regime, there was little incentive for companies to supply technical information and contribute to efficient risk assessment. It was therefore seen as a failure because even if the risk assessment concluded the existence of risk, the use of hazardous substances was hardly ever restricted as a direct result of the assessment process (European Commission, 1998). Although REACH has retained the instrument of restrictions (see Art. 67-73 REACH), the very existence of the authorisation procedure in $\mathrm{REACH}$ is intrinsically related to this failure. By giving companies the responsibility to conduct risk assessment on hazardous substances, the procedure aims to facilitate regulatory decision making by reversing the burden of proof (see Chapman, 2007, p. 69; European Commission, 2001; Koch \& Ashford, 2006, p. 40). 
To this end, the procedure consists of two stages. First, SVHCs are included in the so-called Candidate List. The inclusion of SVHCs requires companies to communicate information about products containing the substance (Art. $7 \& 33$ REACH). Second, SVHCs in the Candidate List are selected for eventual inclusion in Annex XIV of REACH. As soon as a substance is included in Annex XIV, companies wishing to use it in industrial processes need to apply for authorisation. The burden of proof is reversed insofar as companies applying for authorisation need to conduct extensive risk assessment for specific uses of substances for which authorisations are applied for. ${ }^{1}$ Decision making at both stages can be distinguished as hazard-based at the first stage, i.e., SVHC inclusion in the Candidate List, and riskbased at the second stage, i.e., SVHC inclusion in Annex XIV (see Hansen \& Blainey, 2006). The hazard-based inclusion means that substances can be identified as SVHCs based on their molecular structure, i.e., their intrinsic properties. If a substance is in line with the SVHC criteria laid down in REACH Article 57, no additional information is needed to include the substance in the Candidate List. The risk-based inclusion means that substances are selected for Annex XIV not only because of their intrinsic properties, their hazard, but also because of the volume and uses of the substance, as well as exposure data for certain populations (Art. $58 \mathrm{REACH}$ ). Although risk-based selection falls short of full-fledged risk assessment, decision making is more complex since additional information needs to be processed to make such selections. Since this information is meant to give an indication of the level of risk, the selection of SVHCs from the Candidate List is referred to as prioritisation.

Since ECHA has a fairly common organisational structure for EU agencies, I here discuss only those decision making bodies that are essential for the authorisation procedure. In order to include a substance as SVHC in the Candidate List, it first needs to be proposed. This can be done by each Member State and the Commission (Art. 58). If a substance is proposed as SVHC, a respective dossier needs to be submitted; in the case of the Commission, it is ECHA that submits a dossier on behalf of the Commission. A proposed substance is then included in the Candidate List by the Member State Committee (MSC) (Art. 59 REACH). The MSC is an ECHA body that is composed of national representatives, one per Member State, usually from the national regulatory authority dealing with chemicals (see Art. $85 \mathrm{REACH}$ ). The MSC, however, is not a clearcut technical committee; although it consists of experts from national regulatory authorities, it is political in the sense that national interests are explicitly represented

\footnotetext{
${ }^{1}$ In this article, I deal only with the inclusion of SVHCs in Annex XIV and not actual applications for authorisations. In the time period covered by the empirical analysis, mid-2008 until the end of 2012, no authorisations were submitted.
}

in committee deliberations (see ECHA, 2010). As such, those nominated for the committee are wearing different "hats", being simultaneously members of an agency committee, policy experts and representatives of national interests (Egeberg \& Trondal, 2007).

Regarding the prioritisation of SVHCs, ECHA is entitled to select substances from the Candidate List and recommend priority substances for Annex XIV inclusion; by doing so, ECHA has to take into account the opinion of the MSC (Art. 58 REACH). Prioritisation is accompanied by consultation, whereby stakeholders are invited to submit comments on the prioritised substances. The recommendation, including the prioritised substances, is then sent to the Commission which is entitled to include SVHCs in Annex XIV by way of comitology (Art. $133 \mathrm{REACH}$ ). This article refers to the respective comitology legislation and specifies that decisions on Annex XIV inclusion are to be made through the regulatory procedure with scrutiny. The new system of delegated and implementing acts brought about by the Lisbon Treaty, and replacing the system of comitology, has not yet affected these provisions and, for the time being, decisions are made in line with the old comitology system.

\section{Conceptual Framework}

A popular framework of analysis regarding EU agency legitimacy is the distinction between input and output legitimacy (see Scharpf, 1999; also Borrás, Koutalakis, \& Wendler, 2007; Griller \& Orator, 2010; Krapohl, 2008; Weimer, 2008). Input legitimacy refers to the institutional arrangements of political systems that ensure equal participation through elections and subsequent chains of delegation to governments and administrative bodies. Output legitimacy refers to effective problem solving in the sense that policy outcomes meet citizens' preferences. An important part of the scholarly debate is the question of whether input and output legitimacy are positively or negatively correlated, i.e., whether decreasing input legitimacy necessarily leads to increasing output legitimacy, and vice versa, or whether both forms of legitimacy are mutually reinforcing (see e.g., Bellamy, 2010). This fundamental question, to which I don't give a general answer, provides an important backdrop for the argument developed in this section. Drawing on a conceptual discussion of the input-output framework, and in reference to my earlier question regarding assessing the legitimacy of EU agency decision making, I argue that throughput legitimacy is the better normative standard (see Schmidt, 2013).

Generally, agencies are created with certain expectations relating to their ability to process technical information and produce more effective policy outcomes. The decrease of input legitimacy is accepted, because agencies promise increased output legitimacy, which in certain political systems or policy areas make agency creation more desirable or even feasible (Ma- 
jone, 1996; Scharpf, 1999). Hence, while advocates of input legitimacy stress the importance of equal participation for every citizen, even at the risk of producing sub-optimal policy outcomes, advocates of output legitimacy stress the problem solving capacities of experts (see Bellamy, 2010). Hence, if one were to subscribe to the assumption of negative correlation between input and output legitimacy, a causal relation could be established, generating clear theoretical expectations. If input legitimacy increases, output legitimacy decreases, and vice versa. This expectation has been shown to hold with regard to the European Medicines Agency EMA and the European Food Safety Authority EFSA (Krapohl, 2008). While the causal relation generating theoretical expectations is rather straightforward, there remains a problem of measurement which does not only affect the conceptual foundation of the input-output model. If the seemingly solid conceptual foundation becomes fragile, it also questions normative arguments which are based on the inputoutput model and specifically the emphasis on effective problem solving as output legitimacy.

The normative standard of output legitimacy accepts decreasing input legitimacy not only for practical reasons, but also because it is believed that agencies' expertise will lead to more effective policy outcomes. To this end, participation in decision making processes, in contrast to elections as a form of input legitimacy, can be limited to experts capable of giving well-informed justifications for decisions. This means that, whereas public participation through elections does not require deliberation per se, expert decision making is intrinsically related to deliberation and sophisticated reasoning (Moore, 2014, p. 67). This is why some scholars advocate that certain issues are left to experts since citizens are neither capable of nor interested in partaking in such decision making processes. If expert decision making then meets these citizens' preferences, output legitimacy is given. Yet, advocating expert decision making hinges on the assumption of unequivocal standards of output legitimacy, i.e., policy outcomes meeting citizens' preferences effectively. The problem here is that even highly technical problems imply an array of possibly conflicting preferences among multiple actors regarding policy outcomes. If these actors hold conflicting preferences on such outcomes, invoking output legitimacy as a normative argument is problematic, because objective measurement of policy effectiveness is inevitably skewed. In order to evade problems of measuring output legitimacy, scholars have applied indicators derived from accountability concepts (see Kraphol, 2008). While such indicators allow for instructive empirical analysis, the question remains whether they actually measure output legitimacy.

A similar observation can be made regarding input legitimacy, given that some of the indicators used to assess input legitimacy seem to address decision making processes by and through EU agencies (see Borrás et al., 2007; Krapohl, 2008). Yet, understanding input legitimacy more in terms of delegating chains by which electorates or governments delegate tasks to representative or administrative bodies respectively, seems at odds with these indicators. Alternatively, the involvement of the European Parliament (EP) in the act of secondary legislation that delegates tasks to the agency has been used as an indicator of input legitimacy (Krapohl, 2008). The assumption being that the application of the former co-decision procedure, and current ordinary legislative procedure, increases input legitimacy due to the involvement of the EP, given that there is a clear chain of delegation from the basic legitimation through elections to a delegating act at the EU level. However, agencies have been increasingly created by secondary legislation involving both the EP and the Member States in the Council. Moreover, after years of intensive discussions, EU institutions finally agreed on a common approach regarding the creation and operation of agencies, which, for the time being, concluded the struggle for a systematic framework of EU agencies (see European Commission, 2008). As a result, input legitimacy has lost some of its analytical meaning as normative criterion given that the $E P$, in the course of the legislative procedure, has often managed to amend delegating acts in its favour (Lord, 2011).

Hence, due to the conceptual problems with the input-output framework, I argue that throughput legitimacy is the better normative standard to assess the legitimacy of decision making through EU agencies (see Schmidt, 2013). This standard seems promising, because regardless of the conceptual problems of the input-output framework, the causal relation is compelling and based on solid argumentation. At the heart of the matter here is the tension between expert decision making and democratic participation of the public (see Holst \& Molander, 2014). While decision making in complex societies has to rely on expertise to deal with technical difficulties, this also limits equal participation for the simple fact that not everybody is an expert on the issue. This tension resonates with the question of whether input and output legitimacy are positively or negatively correlated. As Schmidt (2013, p. 3) notes, the concept of throughput legitimacy provides a better understanding of the input-output relation and is thus a normative standard that brings together the vast literature dealing with questions of decision making processes.

The key question then is how limited access to decision making and democracy can be reconciled; or more specifically, what kind of organisational arrangements are required to ensure legitimate decision making by experts (Holst \& Molander, 2014). In general, throughput legitimacy refers to the rules and procedures by which decisions are made in and by organisations (Bekkers \& Edwards, 2007; Majone, 1980). As Majone points out, a key feature of legitimate decision making is the acceptability of decision outcomes by citizens, or 
stakeholders as intermediaries of societal interests including citizens. It does not necessarily follow that concrete decision outcomes are indeed accepted by stakeholders. Yet, as a normative standard, throughput legitimacy assesses the extent to which decision making procedures can be accepted from a theoretical point of view (see also Schmidt, 2013, pp. 9-10).

In line with Moore (2014, pp. 71-72), such acceptability can be distinguished with regard to internal and external legitimacy. Internal legitimacy refers to acceptability by those who were part of the decision making process, hence "inside the room" as Moore puts it, and thus speaks to various indicators of throughput legitimacy identified in the literature, such as participation and consultation. External legitimacy refers to acceptability "outside the room" and thus speaks to indicators such as transparency and public justification. This distinction helps to further substantiate the argument that throughput legitimacy is the better normative standard of decision making processes. It allows for a fine-tuned analysis of the organisational structures of decision making, and whether these structures facilitate the acceptability of decision outcomes. Depending on the normative point of view, one might argue in favour of internal or external legitimacy, i.e., whether expert decision making should be acceptable to other actors inside the room or to stakeholders outside the room (see Holst \& Molander, 2014; also Pedersen, 2014).

Yet, a key feature of legitimate decision making is that the boundaries between those inside and outside the room are not entirely closed off (see Moore, 2014, pp. 72-74). If this were so, as Moore points out, "then what is left to those outside the room is only acclamation or rejection" (Moore, 2014, p. 72). Hence, legitimate decision making implies that decisions can be contested by those outside the room, even though informally and infrequently, without completely removing the boundaries to expert decision making inside the room. Drawing on the boundary between internal and external legitimacy, I assess to what extent decision making is legitimate in the REACH authorisation procedure. In the following empirical sections, it will be shown that legitimacy is insufficient because during the implementation process, boundaries have been re- drawn in favour of internal legitimacy, thus reducing the acceptability of decision outcomes by multiple stakeholders. While a lack of inclusiveness and transparency might be justified with a need for free deliberation and discretionary decision making by experts, the implementation of the authorisation procedure does not live up to such deliberative norms.

\section{The Inclusion of SVHCs in the Candidate List and Annex XIV}

As mentioned before, three types of SVHCs are distinguished in Article 57 of REACH, i.e., CMR, PBT and EC substances. Regarding the three types, CMRs are the easiest to identify because their type is based on definitive criteria. If the substance in question has received harmonised classification at the EU level, even in the old regime, and is, therefore, listed in the CLP as carcinogenic, mutagenic or toxic for reproduction, it can already be known that the substance has SVHC properties. In contrast to CMRs, the identification of PBTs and ECs is more complex because their type is based on "open" criteria, i.e., a thorough examination of the substance is needed to determine its properties and the outcome of this determination is not known in advance. Hence, it can be decided after such examination that the proposed substance does not fulfil PBT and EC criteria as laid down in $\mathrm{REACH}$. As a result, there is no predetermined number of SVHCs which are known to be subject to the authorisation procedure. Shortly before the adoption of REACH, the Commission estimated that around 1,500 substances could be identified as SVHCs. ${ }^{2}$ Although almost thousand substances were known to have SVHC properties before the adoption of REACH, in the process of implementation, from mid-2008 until the end of 2012, only a limited number of 138 SVHCs has been included in the Candidate List (see Table 1). The reason for this is an agreement between Member States and the Commission not to propose all substances known to be SVHCs.

2 The number is based on 900 substances known to have SVHC properties, whereas 600 were expected to emerge through the REACH requirement for the registration of all substances on the market; see European Commission (2006).

Table 1. Number of SVHCs included in the candidate list, 2008 to 2012.

\begin{tabular}{|c|c|c|c|c|}
\hline Round & Date & & No. of SVHCs included & No. of SVHCs in the Candidate List \\
\hline 1 & October & 2008 & 15 & - \\
\hline 2 & January & 2010 & 15 & 30 \\
\hline 3 & June & 2010 & 8 & 38 \\
\hline 4 & December & 2010 & 8 & 46 \\
\hline 5 & June & 2011 & 8 & 54 \\
\hline 6 & December & 2011 & 20 & 74 \\
\hline 7 & June & 2012 & 13 & 87 \\
\hline 8 & December & 2012 & 54 & $141(138)$ \\
\hline
\end{tabular}

Note: After the eighth round, 138 substances were included in the Candidate List. The number of decisions (141) is higher because for three substances the Member State Committee made a decision twice. Furthermore, the number of proposed substances is higher as well (145) because not all substances proposed were included. In the second round, one substance was formally included in March. 


\subsection{Candidate List}

The agreement of the Member States and the Commission can best be understood when contrasted with the demand voiced by the environmental and public health committee in the EP during the legislative process of REACH. The committee inserted an amendment that all substances known to have SVHC properties shall be included in the Candidate List (European Parliament, 2005). The amendment was rejected by the Council that insisted that SVHCs may be included (Council, 2006). Hence, the agreement of the Member States and the Commission to not propose all known SVHCs entails two basic consequences. First, if not all known SVHCS shall be included; those that shall be included need to be identified first. As shown in Table 1, known SVHCs are not included at once, but in subsequent rounds with a varying number of substances. Unsurprisingly, this staggered approach was much criticized by NGOs, trade unions and members of the EP's environmental and public health committee (see e.g., Chemtrust et al., 2008; European Parliament, 2008, 2010). According to these stakeholders, the limited number of proposed SVHCs only serves the interests of industries at the expense of human health and environmental protection. In order to support such criticism and raise awareness, various lists containing hundreds of substances were created, applying the legal criteria of REACH, which could and should be included immediately. ${ }^{3}$

Second, if not all known SVHC shall be included in the Candidate List; an approach is needed regarding specific substances and whether or not they shall be included. Since REACH does not contain any provisions in this respect, ECHA convened a workshop shortly after the first round of inclusion (ECHA, 2009a). The workshop was attended by representatives of the Member States and the Commission and the purpose of the workshop was to clarify which and how the known SVHCs shall be included in the Candidate List. To this end, an informal expert group, consisting of experts from six Member States (The Netherlands, Germany, Sweden, Denmark, Austria and France), came up with a "source list" of known SVHCs from which substances could be eventually proposed for authorisation. It was also concluded that a coordinative framework for decision making should be set up, in which Member States shall coordinate the decisions to propose specific SVHCs for the Candidate List. This framework is referred to as Risk Management Options (RMO) analysis. The RMO aims to reflect on the effectiveness of various options to deal with a substance, and based on such reflection, a decision for one or the other regulatory instrument would be made. The main respective

3 See for instance the SIN list ("Substitute it now"), see www.sinlist.org. options are the regulatory instruments of REACH, thus authorisation and restriction of substances, as well as the option not to regulate a substance at all. In a nutshell, the RMO analysis aims to share information among Member States, and to coordinate national activities regarding the proposal of substances for the authorisation procedure. Another important reason for the set up of the RMO analysis concerns the role of the MSC regarding SVHC inclusion in the Candidate List.

Formally, the MSC is entitled to include substances, yet the mandate is formulated as such that it can only make a decision based on the intrinsic properties of a substance, i.e., hazard-based inclusion (see ECHA, 2007). This means that if a substance, which is known to have SVHC properties, is proposed by one Member State or the Commission, the MSC has de facto no choice but to include the substance in the Candidate List, even though one or more Member States in the committee might disagree. This applies mainly to CMRs, because they have received harmonised classification, and are therefore listed in the CLP regulation. According to the REACH criteria on CMRs, existing harmonised classification cannot be challenged within the authorisation procedure. In fact, most of the 138 substances in the Candidate List are CMRs for which harmonised classification had been agreed on before.

\subsection{Annex XIV}

In the time period covered by the empirical analysis, 22 SVHCs have been included in Annex XIV, thus prioritised from 138 substances included in the Candidate List. In the implementation process, two inter-related features of the decision making appear noteworthy. First, it appears from the empirical evidence that ECHA, when making recommendations on prioritised substances, does not falter when faced with Member States' opposition (see ECHA, 2011b; also ECHA, 2011c). It regularly adjusts technical details of the recommendation in line with the set rules and procedures, yet substantial changes are not included in the recommendations. In case of politically salient issues, Member States' opposition is then expressed as minority positions and attached to the opinion of the MSC. Second, the Commission plays a crucial role here because it is entitled to transmit the agency recommendation in a draft regulation for comitology decision making. The 22 substances included in Annex XIV until the end of 2012 were based on three rounds of recommendations by ECHA in which 28 substances were prioritised. If the 28 substances prioritised by ECHA represent 28 cases of decision making, the Commission has altered some technicalities pertaining to individual substances in the recommendation in 17 cases, i.e., in two-thirds of all cases. Hence, the Commission is not merely rubberstamping ECHA's recommendation. 


\section{Discussion: What Kind of Legitimacy?}

In the conceptual discussion, it was argued that throughput legitimacy is the better normative standard to assess the legitimacy of decision making processes. A distinction was made between internal legitimacy, acceptability of decision outcomes by those inside the room, and external legitimacy, acceptability of decision outcomes by those outside the room. This distinction highlights the boundaries drawn between those inside and those outside the room, and thus allows for a finetuned analysis of the organisational structures of decision making. While the empirical section presented the authorisation procedure in a linear structure, in this section I discuss the question of legitimate decision making based on the conceptual distinction between internal and external legitimacy. By doing so, I hope to show how the boundaries between internal and external legitimacy have been redrawn, and why this redrawing negatively affects throughput legitimacy.

\subsection{Prospects of External Legitimacy in the REACH Authorisation Procedure}

A number of recitals and provisions of REACH refer to transparency and participation. In the authorisation procedure specifically, stakeholders such as industry associations, trade unions and NGOs are admitted to the meetings of the MSC as observers. The nonconfidential versions of the minutes are published and technical documentation of SVHCs proposals is also publicly available. Since the MSC is more than just an expert committee, if vital national interests are affected through SVHC proposals, controversies are brought into the open and minority opinions are made public (see ECHA, 2009b; ECHA, 2012). Although stakeholders have no formal say in the decision making, their scrutiny with regard to deliberative processes provides for external legitimacy, given that stakeholder organisations are assumed to represent those outside the room. However, in the majority of cases in which SVHCs are included in the Candidate List, the MSC does not deliberate. Since most of the 138 substances included in the Candidate List are CMRs, the decision outcome is pre-determined and in many cases these substances are not even considered by the committee, but directly included. As a result, the prospect of the MSC as a deliberative forum is only truly materialized when PBT or EC substances are proposed for the Candidate List. These substances, however, are the minority of SVHCs in the Candidate List.

The prioritisation of SVHCs for Annex XIV inclusion, likewise, is formally characterized by transparency and access of stakeholders. The methodology of the prioritisation, developed and revised together with Member States, is publicly available and each round of prioritisation is accompanied by public consultation. If the prioritisation of ECHA is faced with Member States' opposition, minority opinions are made public and ECHA provides extensive documentation, justifying decisions on prioritisation (see ECHA, 2011a). While the prioritisation of ECHA seems to support external legitimacy, the following step in the procedure, comitology decision making, is not as straightforward (e.g. Lee, 2014b).

In the literature, comitology is sometimes seen as a specific form of supranational governance, in which deliberation prevails and factual arguments are more important than tit-for-tat bargaining (Joerges \& Neyer, 1997). However, comitology is also notoriously nontransparent and largely excludes the EP, despite the right of scrutiny. As Blom-Hansen and Brandsma (2009) show, comitology decision making is not only characterized by deliberative decision making by experts, but also by intergovernmental bargaining. Indeed, in two out of three rounds of Annex XIV inclusion, the Commission proposal was adopted with a qualified majority, whereas only in one case, unanimity was achieved. This means that good arguments and deliberation are not always sufficient to aggregate Member States' preferences. In some cases when national preferences are affected, voting is needed to make a decision. Thus, some of the rules and procedures which seem to provide external legitimacy, at both stages of the procedure, are perceived by some actors as constraints. By invoking images of output legitimacy, these actors attempt to redraw the boundaries between internal and external legitimacy. If this redrawing favours internal legitimacy over external legitimacy, this might turn constraints into opportunities.

\subsection{Redrawing Boundaries in Favour of Internal Legitimacy}

The set up of the RMO analysis is supposed to increase output legitimacy by deciding on the most effective instrument to deal with SVHCs. It might well be argued that SVHCs which are not used in high volumes or which are essential for certain industrial processes are better not proposed for the authorisation procedure; regulatory resources and expertise are better spent on priority substances. However, such reasoning does not meet NGOs' and trade unions' preferences. If it is assumed that these actors legitimately represent citizens' interests regarding environmental and human health, the limited inclusion of SVHCs in the Candidate List can hardly be seen as increasing output legitimacy. Moreover, since RMO is not mentioned in the legal provisions of REACH, Member States' experts are meeting in the framework of a Commission expert group. To this group, neither industry nor NGOs have formal access and no supporting documentation regarding decision making is made public (European Commission, 2013). ${ }^{4}$

${ }^{4}$ The RMO analysis is becoming increasingly formalised and 
From the perspective of many Member States, the lack of inclusiveness and transparency is needed to ensure technical, non-political deliberation among experts (MS\#1; see also Chemical Watch, 2011; European Commission, 2011). However, if boundaries are to be redrawn because the MSC does not provide the right forum of deliberation, it should not happen at the expense of external legitimacy.

The RMO analysis is not only informal, but it is also not legally binding and neither Member States nor the Commission can be forced to coordinate their actions before submitting a proposal. After all, SVHC proposals are not merely technical issues, but reflect national interests in getting particular groups of substances in the Candidate List (EXP; MS\#4). Hence, not only does the RMO redraw boundaries towards internal legitimacy, the deliberative potential of internal legitimacy, for instance through experts' peer review, is not even fully realized. This is the case if no deliberation in the context of RMO takes place. While this might change in the future, in the first years of REACH implementation, the lack of coordination and deliberation is obvious. Not only were the substances proposed without RMO analysis, but also some substances were discarded by some Member States only to be proposed by others (MS\#2). In the eighth round of identification in 2012, the Commission, which is a stern advocate of RMO, asked ECHA to propose more than thirty substances without conducting RMOs (see Table 1). The perceived or claimed output legitimacy of RMO analysis is undermined in such cases, if the proposed substances were not of high priority (MS\#3). Instead, the Commission asked ECHA to propose these substances in order to keep their political promise to have 136 substances in the Candidate List by the end of 2012 (COM\#1; COM\#2; also Chemical Watch, 2010).

At the stage of substance prioritisation, similar redrawing can be observed. It has been said that the Commission is not rubber-stamping ECHA recommendations, given that in two thirds of all recommended substances, specific changes were made. In some cases, substances opposed by Member States during prioritisation were removed altogether from the recommendation. Admittedly, it is the prerogative of the Commission to deviate from the agency recommendation when issuing draft regulations to the comitology committee. In the context of comitology decision making, the Commission needs to garner broad support in the committee to ensure effective implementation at the national level (Joerges \& Neyer, 1997). From this perspective, consultations with industry and Member States prior to formal decision making in comitology committees actually increases legitimacy, if such con-

some documentation, albeit limited, might be released. These developments, however, are rather recent inventions beyond the scope of this article. sultation contributes to effective problem solving. Accordingly, the Commission in justifying their decisions invokes images of output legitimacy, as it is argued that other regulatory instruments than authorisation are more effective to deal with some of the substances (COM\#1; also Herbatschek, Bergkamp, \& Mihova, 2013). However, similar to the RMO, boundaries are redrawn, because in contrast to public consultation and extensive deliberation of ECHA prioritisation, the decision making processes in the Commission are informal and non-transparent. As a result, access to the Commission is crucial. While Member States were able to reiterate their opposition regarding the inclusion of contested substances (MS\#3), NGOs claim that the Commission was also under heavy lobbying pressure from industry to remove these substances (NGO).

However, the opposition by companies and Member States is motivated by economic concerns for vital industries. Again, invoking images of output legitimacy is questionable, given the diverging preferences of NGOs and sometimes trade unions. Irrespective of the aforementioned conceptual problem of output legitimacy, arguing that the Commission relies on these consultations in order to profit from stakeholders' expertise is unconvincing in the age of EU agencification. The rationale behind agencies' creation is the expectation that they develop expertise that contributes to regulatory decision making. In the context of agency decision making, Member States' experts and stakeholder are involved in decision making processes according to set rules and procedures. The redrawing of boundaries at the second stage of the authorisation procedure, however, favours those actors which have preferential access to the Commission, namely industry and salient Member States (EXP). This somewhat nullifies the elaborate procedure of ECHA decision making which is based on inclusiveness, consultation and transparency. Although these procedures are not without problems, from this perspective, the argument of Majone (2010) for strong EU agencies is appealing. Regardless of whether one advocates expert decision making or inclusive participation, thus invoking output and input legitimacy respectively, decision making by and through agencies based on set rules and regulations certainly increases throughput legitimacy. This seems of particular importance in policy areas in which output legitimacy is faced with limitations due to conflicting preferences and diverging perceptions of policy effectiveness. In set rules and procedures, boundaries between internal and external legitimacy are drawn and cannot be easily redrawn through informal processes.

\section{Conclusions}

This article set out to assess the legitimacy of decision making in the REACH authorisation procedure. Based 
on a discussion of the input-output framework of legitimacy, it was argued that throughput legitimacy is the better normative standard. This is particularly the case in highly contested policy areas, in which the notion of policy effectiveness defies objective standards of measurement. The adoption of REACH came about after a controversial legislative process, due to competing preferences on industrial competitiveness versus human health and environmental protection. The intricacies of decision making in the authorisation procedure are the result of these competing preferences. During the implementation process, such intricacies provide opportunities and constraints for multiple actors, and these actors invoke different images of legitimacy to pursue their preferences. It was shown that boundaries between internal and external legitimacy are redrawn towards the former, yet without living up the normative standards of expert deliberation and justification associated with internal legitimacy. Although this affects the acceptability of decision outcomes in general, some actors nevertheless enjoy preferential access to decision making bodies. The resulting insufficiency of legitimacy is due to the alteration of rules and procedures of decision making during the implementation of the authorisation procedure. The empirical material presented here is thus important for complementing the vast literature on REACH, as it sheds light on the way ambiguous legislative provisions are materialized in the implementation process.

\section{Acknowledgements}

The author wishes to thank the editors of this special issue as well as the anonymous reviewers. Their criticisms and suggestions were of tremendous help to improve the final version of this article. All remaining errors are my responsibility.

\section{Conflict of Interests}

The author declares no conflict of interests.

\section{References}

Bekkers, V., \& Edwards, A. (2007). Legitimacy and democracy: A conceptual framework for assessing governance practices. In V. Bekkers, G. Dijkstra, A. Edwards, \& M. Fenger (Eds.), Governance and the democratic deficit: Assessing the democratic legitimacy of governance practices (pp. 35-60). Aldershot: Ashgate Publishing Limited.

Bellamy, R. (2010). Democracy without democracy? Can the EU's democratic "outputs" be separated from the democratic "inputs" provided by competitive parties and majority rule? Journal of European Public Policy, 17(1), 2-19.

Bergkamp, L. (Ed.). (2013). The European Union REACH regulation for chemicals. Law and practice. Oxford: Oxford University Press.

Blom-Hansen, J., \& Brandsma, G. (2009). The EU comitology system: Intergovernmental and deliberative supranationalism. Journal of Common Market Studies, 47(4), 719-740.

Borrás, S., Koutalakis, C., \& Wendler, F. (2007). European agencies and input legitimacy: EFSA, EMeA and EPO in the post-delegation phase. Journal of European Integration, 29(5), 583-600.

Busuioc, M., Groenleer, M., \&Trondal, J. (Eds.) (2012). The agency phenomenon in the European Union. Manchester: Manchester University Press.

Chapman, A. (2007). Democratizing technology. risk, responsibility and the regulation of chemicals. London \& Sterling, VA: Earthscan.

Chemical Watch. (2010, March 25). New EU chiefs put REACH centre-stage. Retrieved from http://chemica Iwatch.com/3525/new-eu-chiefs-put-reach-centrestage

Chemical Watch. (2011, February 11). EU states in silent protest over MEPs' role in Caracal. Retrieved from http://chemicalwatch.com/6488/eu-states-insilent-protest-over-meps-role-in-caracal

Chemtrust, Center for International Environmental Law (CIEL), European Environmental Bureau, Friends of the Earth Europe, Greenpeace, Health and Environment Alliance, Women in Europe for a Common Future, \& WWF. (2008, October 28). First REACH hazardous chemicals list is a drop in the ocean. Retrieved from http://www.chemtrust.org.uk/wpcontent/uploads/PR_first_candidate_list_200810_FINAL_pr2.pdf

Council. (2006). Common position (EC) No 17/2006 of 27 June 2006 adopted by the Council, acting in accordance with the procedure referred to in Article 251 of the Treaty establishing the European Community, with a view to adopting a Regulation of the European Parliament and of the Council concerning the Registration, Evaluation, Authorisation and Restriction of Chemicals (REACH), establishing a European Chemicals Agency, amending Directive 1999/ 45/EC of the European Parliament and of the Council and repealing Council Regulation (EEC) No 793/93 and Commission Regulation (EC) No 1488/ 94 as well as Council Directive 76/769/EEC and Commission Directives 91/155/EEC, 93/67/EEC, 93/ 105/EC and 2000/21/EC. Brussels: Council of the European Union.

ECHA. (2007). Guidance for the preparation of an Annex XV dossier on the identification of substances of very high concern (June 2007). Helsinki: ECHA.

ECHA. (2009a). Proceedings of the workshop on the candidate list and authorisation as risk management instruments, Helsinki, 21-22 January 2009. Helsinki: ECHA.

ECHA. (2009b). Minutes of the 8th Meeting of the 
Member State Committee (MSC-8), 18-20 May 2009 (MSC/M/08/2009 Final). Helsinki: ECHA.

ECHA. (2010). Minutes of the 15th Meeting of the Member State Committee (MSC-15), 1-3 December 2010 (MSC/M/05/2010). Helsinki: ECHA.

ECHA. (2011a). Responses to comments document (RCOM) on ECHA's draft 3rd recommendation for the group of recommended Cobalt(II) substances (20 December 2011). Helsinki: ECHA.

ECHA. (2011b). Minutes of the 18th Meeting of the Member State Committee (MSC-18), 25-27 May 2011 (MSC/M/018/2011). Helsinki: ECHA.

ECHA. (2011c). Minutes of the 21st Meeting of the Member State Committee (MSC-21), 7-9 December 2011 (MSC/M/021/2011). Helsinki: ECHA.

ECHA. (2012). Minutes of the 27th Meeting of the Member State Committee (MSC-27), 10-13 December 2012 (MSC/M/027/2012). Helsinki: ECHA.

Egeberg, M., \& Trondal, J. (2007). National agencies in the European administrative space: Government driven, Commission driven or networked? Public Administration, 87, 779-790.

European Commission. (1998). Report on the operation of directive 67/548/EEC on the approximation of the laws, regulations and administrative provisions relating to the classification, packaging and labelling of dangerous substances. Directive 88/379/EEC on the approximation of the laws, regulations and administrative provisions relating to the classification, packaging and labelling of dangerous preparations. Regulation (EEC) 793/93 on the evaluation and control of the risks of existing substances. Directive 76/769/EEC on the approximation of the laws, regulations, and administrative provisions of the Member States relating to restrictions on the marketing and use of certain dangerous substances and preparations. Commission working document. SEC (98) 1986 final, 18 November 1998. Brussels: European Commission.

European Commission. (2001). Strategy for a future chemicals policy (COM(2001) 88 final). Brussels: European Commission.

European Commission. (2006). $Q$ and $A$ on the new chemicals policy, REACH (MEMO/06/488). Brussels: European Comission.

European Commission. (2008). European agencies-The way forward, communication from the Commission to the European Parliament and the Council (COM (2008) 135 final). Brussels: European Commission.

European Commission. (2011). Summary record 7th meeting of competent authorities for REACH and CLP (Doc. CA/34/2011 Rev 2). Brussels: European Commission.

European Commission. (2013). 12th meeting of competent authorities for REACH and CLP, roadmap for SVHCs identification and implementation of REACH risk management measures from now to 2020 (Doc. CA/2/2013). Brussels: European Commission.
European Parliament. (2005). Report on the proposal for a regulation of the European Parliament and of the Council concerning the Registration, Evaluation, Authorisation and Restriction of Chemicals (REACH), establishing a European Chemicals Agency (A60315/2005 FINAL, Amendment 214). Brussels: European Parliament.

European Parliament (2008). Notice to members (2008/ 8), question for question time in committee 2008/8 under Rule 187 of the rules of procedure by Satu Hassi (19.11.2008). Brussels: European Parliament.

European Parliament (2010). Letter by Joe Leinen, chairman of the Committee on the Environment, Public Health and Food Safety (IPOL-COM-ENVI D(2010) 15043, 18.03.2010). Brussels: European Parliament.

European Parliament, \& Council of the European Union. (2006). Regulation (EC) No 1907/2006 of the European Parliament and of the Council of $18 \mathrm{De}$ cember 2006 concerning the Registration, Evaluation, Authorisation and Restriction of Chemicals (REACH), establishing a European Chemicals Agency, amending Directive 1999/45/EC and repealing Council Regulation (EEC) No 793/93 and Commission Regulation (EC) No $1488 / 94$ as well as Council Directive 76/769/EEC and Commission Directives 91/155/EEC, 93/67/EEC, 93/105/EC and 2000/21/ $E C, O J L$ 396. Brussels: European Union.

European Parliament, \& Council of the European Union. (2008). Regulation (EC) No 1272/2008 of the European Parliament and of the Council of $16 \mathrm{De}$ cember 2008 on classification, labelling and packaging of substances and mixtures, amending and repealing Directive 67/548/EEC and 1999/45/EC, and amending Regulation (EC) No 1907/2006, OJ L 353. Brussels: European Union.

Gehring, T., \& Krapohl, S. (2007). Supranational regulatory agencies between independence and control: The EMEA and the authorization of pharmaceuticals in the European Single Market. Journal of European Public Policy, 14(2), 208-226.

Griller, S., \& Orator, A. (2010). Everything under control? The "way forward" for European agencies in the footsteps of the Meroni doctrine. European Law Review, 35(1), 3-35.

Hansen, B., \& Blainey, M. (2006). REACH: A step change in the management of chemicals. Review of European Community and International Environmental Law, 15(3), 270-280.

Herbatschek, N., Bergkamp, L., \& Mihova, M. (2013). The REACH programmes and procedures. In L. Bergkamp (Ed.), The European Union REACH regulation for chemicals. Law and practice (pp. 82-170). Oxford: Oxford University Press.

Heyvaert, V. (1999). Coping with uncertainty. The regulation of chemicals in the European Union (Doctoral Dissertation). European University Institute, Florence, Italy. 
Holst, C., \& Molander, A. (2014). Epistemic democracy and the accountability of experts. In C. Holst (Ed.), Expertise and Democracy (ARENA Report No 1/14, pp. 13-35). Oslo: University of Oslo.

Joerges, C., \& Neyer, J. (1997). Transforming strategic interaction into deliberative problem-solving: European comitology in the foodstuffs sector. Journal of European Public Policy, 4(4), 609-625.

Klika, C., Kim, J., \& Versluis, E. (2013). Why science cannot tame politics: The new EU comitology rules and the centralised authorisation procedure of GMOs. European Journal of Risk Regulation, 4(3), 327-334.

Koch, L., \& Ashford, N. (2006). Rethinking the role of information in chemicals policy: Implications for TSCA and REACH. Journal of Cleaner Production, 14, 31-46.

Krapohl, S. (2004). Credible commitment in non independent regulatory agencies: A comparative analysis of the European agencies for pharmaceuticals and foodstuffs. European Law Journal, 10(5), 518-538.

Krapohl, S. (2008). Legitimising supranational risk regulation: The EU pharmaceutical and food safety regimes. German Policy Studies, 4(1), 237-276.

Lee, M. (2014a). The legal institutionalisation of public participation in the EU governance of technology (July 1, 2014, draft for Brownsword, Scotford and Yeung, Oxford Handbook of Law and Regulation of Technology, Forthcoming; ECPR Regulatory Governance Conference, June 2014). Retrieved from http://ssrn.com/abstract $=2461145$

Lee, M. (2014b). Experts and publics in EU environmental law (March 6, 2014, Oxford Handbook of European Union Law, Forthcoming). Retrieved from http://ssrn.com/abstract=2424694

Lord, C. (2011). The European Parliament and the legitimation of agencification. Journal of European Public Policy, 18(6), 909-925.

Majone, G. (1980). Process and outcome in regulatory decision-making. In C. H. Weiss \& A. H. Barton (Eds.), Making Bureaucracies Work (pp. 235-256). Beverly Hills: Sage.

Majone, G. (Ed.). (1996). Regulating Europe. London and New York: Routledge.

Majone, G. (2010). Foundations of risk regulation: Science, decision-making, policy learning and institutional reform. European Journal of Risk Regulation,
1(1), 5-19.

Moore, A. (2014). Democratic theory and expertise. Between competence and consent. In C. Holst (Ed.), Expertise and Democracy (ARENA Report No 1/14, pp. 49-83). Oslo: University of Oslo.

Ossege, C. (2014). Is expertise the driving force? Explaining agency autonomy in the EU. In C. Holst (Ed.), Expertise and Democracy (ARENA Report No 1/14, pp. 393-423). Oslo: University of Oslo.

Pedersen, D. (2014). A dual justification for sciencebased policy-making. In C. Holst (Ed.), Expertise and Democracy (ARENA Report No 1/14, pp. 37-48). Oslo: University of Oslo.

Pesendorfer, D. (2006). EU environmental policy under pressure: Chemicals policy change between antagonistic goals? Environmental Politics, 15(1), 95-114.

Rittberger, B., \& Wonka, A. (2011). Introduction: Agency governance in the European Union. Journal of European Public Policy, 18(6), 780-789.

Sabatier, P. (1978). The acquisition and utilization of technical information by administrative agencies. Administrative Science Quarterly, 23, 396-417.

Scharpf, F. (1999). Governing in Europe-Effective and democratic. Oxford: Oxford University Press.

Schmidt, V. (2013). Democracy and legitimacy in the European Union revisited: Input, output and "throughput". Political Studies, 61, 2-22.

Scott, J. (2009). REACH: Combining harmonisation and dynamism in the regulation of chemicals. In J. Scott (Ed.), Environmental protection: European law and governance (pp. 56-91). Oxford: Oxford University Press.

Selin, H. (2007). Coalition politics and chemicals management in a regulatory ambitious Europe. Global Environmental Politics, 7(3), 63-93.

Stokes, E., \& Vaughan, S. (2013). Great expectations: Reviewing 50 years of chemicals legislation in the EU. Journal of Environmental Law, 25(3), 411-435.

Weimer, M. (2008). Legitimacy through precaution in European regulation of GMOs? From the standpoint of governance as analytical perspective. In C. Joerges \& P. F. Kjaer (Eds.), Transnational standards of social protection. Contrasting European and international governance (ARENA Report No 5/08; RECON Report No 4). Oslo: University of Oslo.

\section{About the Author}

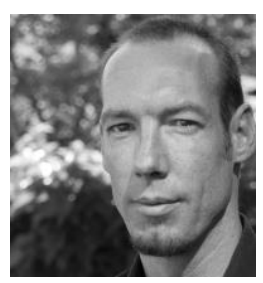

\section{Christoph Klika}

Christoph Klika is Ph.D. candidate at the Faculty of Arts and Social Sciences at Maastricht University. He holds a Master's degree from the University of Vienna and has worked as researcher at the Institute for European Integration Research (Vienna) and the Centre for European Law and Governance (Cardiff). His primary research interests include European integration, EU policy making and risk regulation. He has published on EU risk regulation in the area of GMOs and chemicals policy. 